\title{
EFFECT OF STIRRING RATE ON ELECTROCHEMICAL CODEPOSITION OF Ni-SiC COMPOSITE
}

\author{
Kailash Hamal*, Armila Rajbhandari (Nyachhyon)* ${ }^{*}$ Gobinda Gyawali** and Soo Wohn Lee ${ }^{* *}$ \\ ${ }^{*}$ Central Department of Chemistry, Tribhuvan University, Kirtipur, Kathmandu, Nepal. \\ ** Research Centre for Eco Multi functional Nano Materials, Global Research Laboratory, Sun Moon \\ University, Korea.
}

\begin{abstract}
Nickel-Silicon Carbide (Ni-SiC) composite has been prepared by electrochemical codeposition technique. Nickel sulfamate bath was used along with grain modifier saccharine and cationic surfactant cetyltrimetylammonium bromide (CTAB). The effect of stirring rate was systematically studied and optimized to get well dispersed SiC particles in appropriate amount. Mixed crystalline phase with reinforced [2 111 1 crystal orientation was obtained by XRD analysis. The result revealed that, 250 revolutions per minute $(\mathrm{rpm})$ is optimum stirring rate for the electrochemical codeposition of $\mathrm{Ni}-\mathrm{SiC}$. Coating prepared at $250 \mathrm{rpm}$ showed highest microhardness and lowest coefficient of friction with better surface morphology and well distributed nano $\mathrm{SiC}$ particles.
\end{abstract}

Keywords: Codeposition; Stirring Rate; Morphology; Microhardness; Coefficient of Friction.

\section{INTRODUCTION}

A number of investigations on the preparation of nano composite coating by electrochemical codeposition of second phase particles on metal matrix from electrolytic bath has been done by different scientists [1-4].The codeposition of such second phase particles gives improved microhardness, excellent adhesion, good strength, self lubricating and high temperature inertness, along with chemical and biological compatibility [5]. Due to these improvements electrochemical codepositions become the popular method. Besides these, it has got advantage of low operational cost and high depositional rate. It can be conducted at normal pressure and ambient temperature[6].

Electrochemical codeposition is analogous to a galvanic cell but working in reverse way. The substrate to be plated is placed at cathode of the circuit whereas material to be plated is kept at anode. Both components are immersed in a solution called an electrolytic bath, which contains one or more dissolved metal salts that permits the flow of electricity. Codeposition of the second phase particles into the metal matrix is carried out by dispersion of this particle into the electrolyte. They can incorporate along with growing metal matrix. Generally used second phase particles are hard oxides [7-10] Carbides [11, 12], Nitrides [1], solid lubricants [13], $\mathrm{TiB}_{2}$ [14] and others include diamond, Al flakes [15], nano rods, nano tubes and nano wires [16].

The overall properties of the electrocodeposited materials depend upon the amount of incorporated nano particles in growing metal matrix and their distribution While, the incorporation of these particles depends upon the different parameters like particle characteristics [17], bath composition [18], bath temperature [19], bath $\mathrm{pH}$ [20], stirring rate, types of current applied, variations in current frequency, current density and duty cycle [21]. In order to maintain the particles in suspension and to enhance particles transport towards cathode surface, electrolyte agitation is required. It controls the rate, direction and force with which the particles arrive at the electrode. In the past, much effort has been given to study the effect of ultrasonic, thermal, magnetic as well as physical agitation in electrolyte [7, 22-25]. Study on air agitation was also carried out by Orlovskaja et al [26]. Most of the previous findings indicate that when the agitation rate is enhanced, the incorporation of particles will be automatically increased however drastically increased agitation rate may lead to lesser incorporation of particles.

In present study, we report the preparation and characterization of composite coatings and also studied the effect of stirring rate on properties of composite coatings. After the systematic investigation, stirring rate was optimized to get highest microhardness and lowest coefficient of friction with agglomerate free, well dispersed nano particles in appreciable amount.

\section{MATERIALS AND METHODS}

Experiments were carried out in conventional two electrode electrochemical cell, in which the nickel balls in the titania basket was used as anode whereas SUS

Author for Correspondence: Kailash Hamal, Central Department of Chemistry, Tribhuvan University, Kathmandu, Nepal. 
304 stainless steel substrate of $(4.5 \times 4.5) \mathrm{cm}^{2}$ exposed surface area was taken as cathode. The sulfamate bath was used along with grain modifier saccharine and cationic surfactant CTAB. Electrolytic bath composition and operational conditions used for the codeposition process is given in Table 1. Three different samples were prepared namely (a) S-1, (b) S-2 (c) S-3 which were prepared at $100 \mathrm{rpm}, 250 \mathrm{rpm}$ and $400 \mathrm{rpm}$ respectively. Controlled pulse current was supplied by using Pulse Rectifie, Jiasang Electric Co .Ltd. All the experiments were carried out in continuous stirring condition by using Teflon coated magnetic bar of diameter of $0.5 \mathrm{~cm}$ and length of $2 \mathrm{~cm}$. All reagents used were of analytical grade and obtained from Duksan Pure Chemicals Co. Ltd. Korea. These reagents were prepared in de-ionized water.

Table 1: Bath Compositon and Operating Condition.

\begin{tabular}{llll}
\hline Bath composition & \multicolumn{3}{c}{ Operating condition } \\
\hline $\mathrm{Ni}\left(\mathrm{NH}_{2} \mathrm{SO}_{3}\right)_{2}(\mathrm{~g} / \mathrm{L})$ & 300 & $\mathrm{pH}$ & 4 \\
$\mathrm{NiCl}_{2}(\mathrm{~g} / \mathrm{L})$ & 10 & Temperature $\left({ }^{\circ} \mathrm{C}\right)$ & 50 \\
$\mathrm{H}_{3} \mathrm{BO}_{3}(\mathrm{~g} / \mathrm{L})$ & 40 & Current type & Pulse \\
$\mathrm{CTAB}^{(\mathrm{g} / \mathrm{L})}$ & 0.2 & Duty cycle $(\%)$ & 25 \\
$\mathrm{Saccharine}(\mathrm{g} / \mathrm{L})$ & 2 & Pulse frequency $(\mathrm{Hz})$ & 100 \\
$\mathrm{SiC}(\mathrm{g} / \mathrm{L})$ & 20 & Current density $\left(\mathrm{mA} / \mathrm{cm}^{2}\right)$ & 60 \\
$\mathrm{SiC}$ size $(\mathrm{nm})$ & 270 & Stirring rate $(\mathrm{rpm})$ & varies $(100$, \\
& & & $250,400)$ \\
\hline
\end{tabular}

Surface morphology and microstructure of coatings along with crystal growth and distribution of the incorporated nano $\mathrm{SiC}$ particle on thus prepared samples were characterized by the Scanning electron microscopy (SEM), mini-SEM (nanoeye, Co.).The phase and preferred crystal orientation of $\mathrm{Ni}$ was examined by applying X-ray diffraction (XRD) technique utilizing Rigaku DMAX 2200, XRD, Japan, with $\mathrm{Cu}-\mathrm{k} \alpha$ radiation. Vickers Microhardness Tester (Buehler Ltd., USA) was used to measure the microhardness . Here $100 \mathrm{~g}$ load was applied for 10 seconds on seven different places of the sample at the cross-sectional area. Then the corresponding final values were determined as the average of seven measurements. Tribological properties including coefficient of friction of the samples were evaluated by ball on disc method using Tribometer (CSM Swiss). The used tribological test condition is given in Table 2.
Table 2. Tribological Condition.

\begin{tabular}{lc} 
Tribological Parameters & Operating Conditions \\
\hline Normal load & $2 \mathrm{~N}$ \\
Sliding Seed & $9.42 \mathrm{~cm} / \mathrm{s}$ \\
Total sliding Distance & $56.52 \mathrm{~m}$ \\
Rotating radius & $3 \mathrm{~mm}$ \\
Temperature & $\mathrm{RT}$ \\
Time & $10 \mathrm{~min}$ \\
Lubricants & $\mathrm{No}$ \\
\hline
\end{tabular}

\section{RESULTS AND DISCUSSION}

\section{Surface Morphology}

SEM images in Fig. 1. shows the surface morphology of the coated samples. As can be seen in this figure, the surface morphology of sample S-2 and S-3 seems to have regular surface with smaller grain growth sites. However, sample S-1 has irregular surface morphology with bigger grain growth sites and has agglomerated surface. Such agglomerate surface is not desirable because it reduces the smoothness of the surface and hence in homogeneity in the overall properties of coating. This result clarifies that samples with smooth surface can be prepared at higher stirring rate.

\section{Distribution of Particles}

From the cross-sectional images in Fig. 2, we can clearly observe that Fig.2-b contains the uniformly distributed black $\mathrm{SiC}$ particles in higher amount than in the other two images. This result suggest that the coating prepared at the medium stirring rate i.e. $250 \mathrm{rpm}$ gives the higher incorporation of the nano SiC particle with well dispersion. This result is in good agreement that the incorporation of the nano particles depends upon the residence time of particle in the cathode surface [27]. At low stirring rate, diffusion rate of particle is very slow as a consequence very less amount of particle will reach to the cathode surface. The high stirring speed gives rise to high impinging velocity to the particles towards the cathode. However, high impinging velocity may lead to bounce off the particles from the cathode surface resulting less residence time consequently less incorporation. 

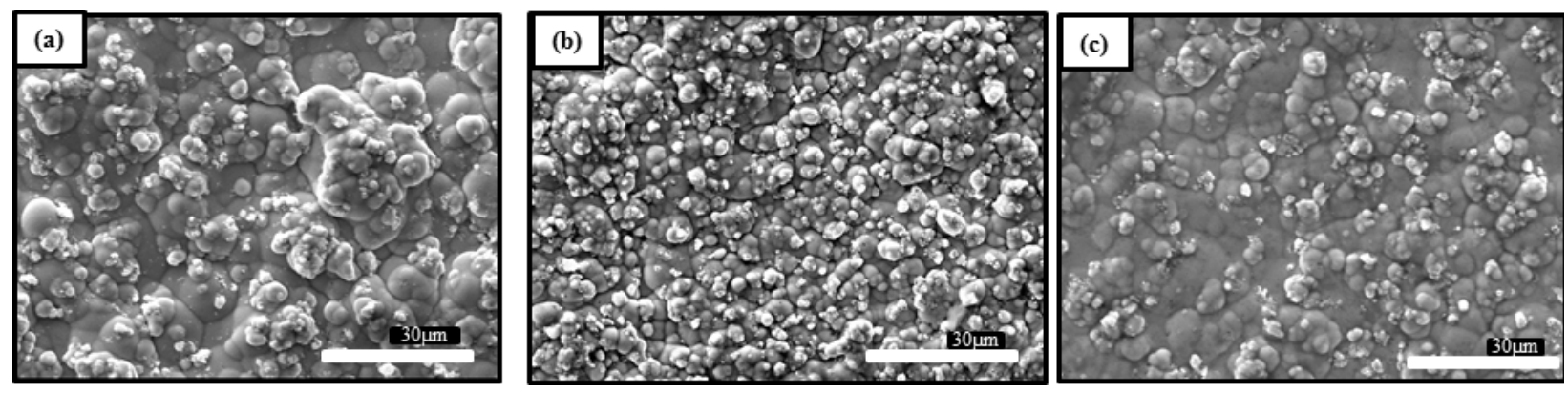

Figure 1: SEM Images of coatings a) S-1, b) S-2 and c) S-3.
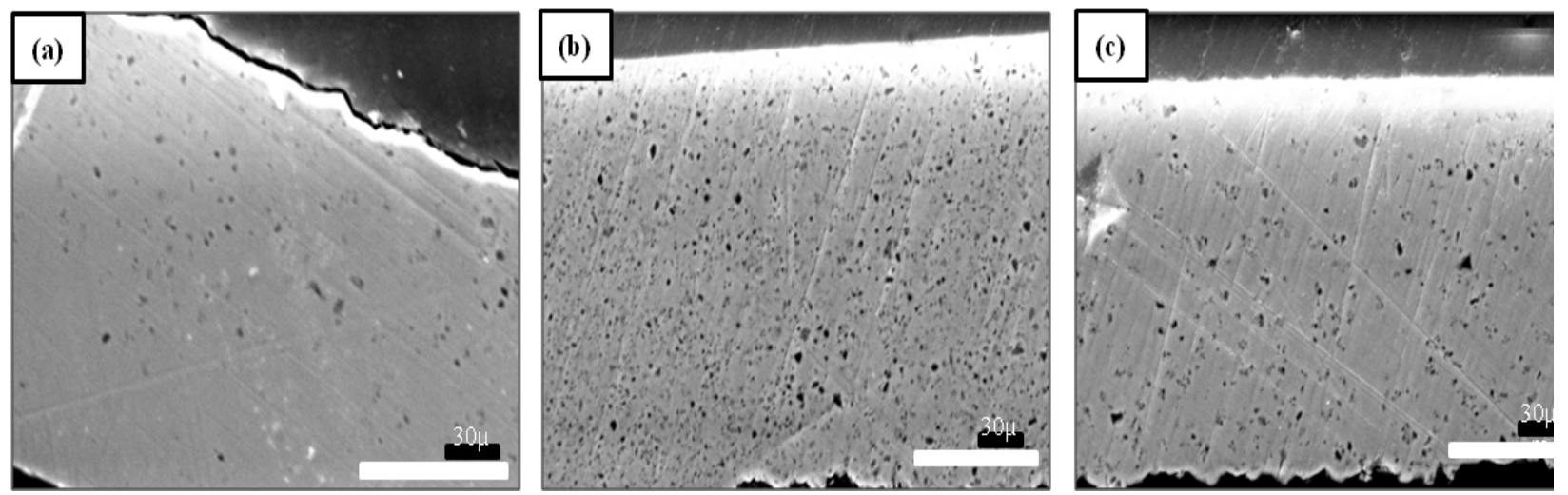

Figure 2 : Cross-sectional SEM Images of Coating a) S-1, b) S-2 and c) S-3.

Phase and Orientation Analysis

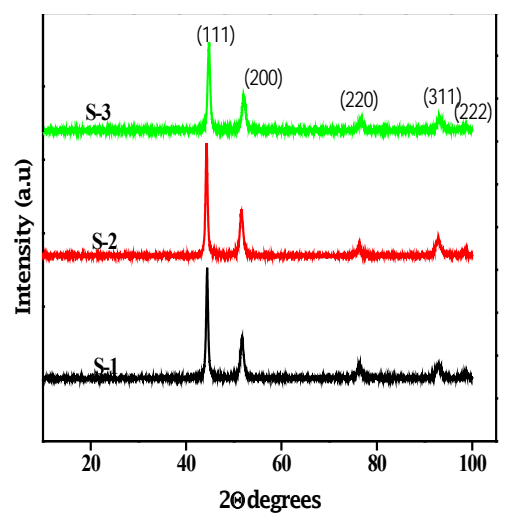

Figure 3: XRD Patterns of Samples S-1, S-2 and S-3.

In Fig. 3 four sharp diffraction peaks were observed at 44,

52,76 and 93 degrees of $2 \theta$ values of (111), (200), (220) and (311) crystal orientation respectively. These peaks are assigned for nickel according to JCPDS data: 04-0850. This sharp picks represents the mixed crystalline phase of coated sample which is found to be different than the pure nickel coating as previously reported by P. Gyoftou et al [21].The highly intense (311) and (111) peak line is attributed to a dispersed[2 $\left.\begin{array}{lll}2 & 1 & 1\end{array}\right]$ orientation which is responsible to higher hardness [28].

\section{Vickers Microhardness}

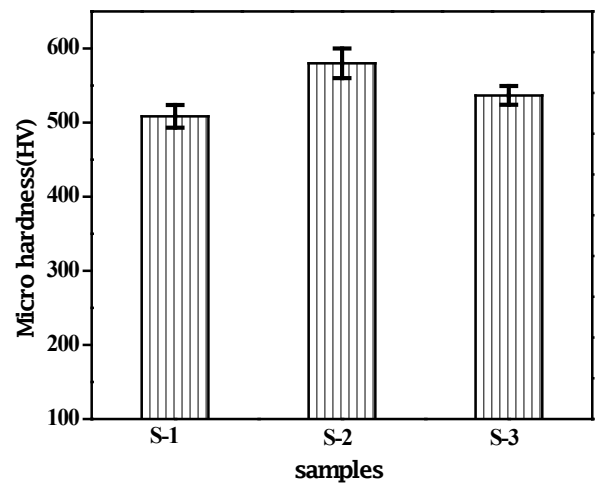

Figure 4: Variation of Vickers microhardness of Ni-SiC coating as a function of different stirring rate.

Fig. 4 shows the bar diagram of microhardness. This diagram indicates that the Vickers microhardness value of coating sample S-2 is higher than the other two samples. This result suggests that the $250 \mathrm{rpm}$

is the optimum stirring rate to produce excellent microhardness. It seems that the coating, which contain larger number of codeposited $\mathrm{SiC}$ particles (as in Fig. 2(b)) exhibit higher Vickers microhardness than other coatings those contains less amount of codeposited $\mathrm{SiC}$ particles, such higher values of the microhardness may resulted from the higher codeposited $\mathrm{SiC}$ particles which induced the hardening effect by unique dispersion method. [29]. 
Tribological Test

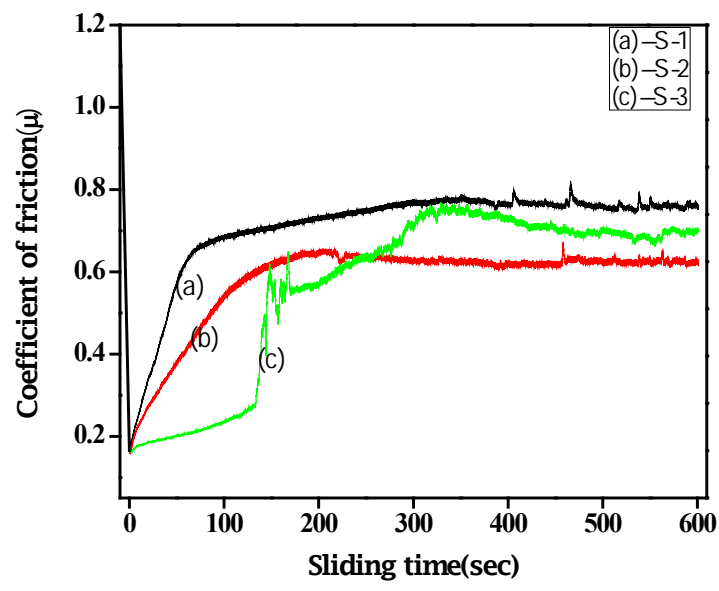

Figure 5: Coefficient of Friction of Samples S-1, S-2 and S-3.

Fig. 5 shows the plots of coefficient of friction as a function of sliding time for the samples S-1, S-2 and S-3. Here curve (a) shows the higher coefficient of friction than others. Curve (b) for sample S-2 shows the initial increase of coefficient of friction value up to 200 $\mathrm{Sec}$ then it changes its nature of i.e, the plateau indicating the constant value. The curve (c) shows the large coefficient of friction value with large fluctuating value. This result infers that, coating prepared at medium stirring rate i.e $250 \mathrm{rpm}$ in this case has the better anti frictional behavior. This result may be due to the homogenous distribution of the reinforced nano $\mathrm{SiC}$ particle with higher amount in coating as can be seen in Fig. 2-b.

\section{CONCLUSION}

$\mathrm{Ni}-\mathrm{SiC}$ composites were successfully coated by electrochemical codeposition technique from a nickel sulfamate bath. The effects of stirring rate on the codeposition behaviors of $\mathrm{SiC}$ were studied. The following conclusions are derived from this studied.

1. The stirring rate of $250 \mathrm{rpm}$ was found to be optimum stirring rate to bring smooth and regular surface morphology of composite coating as indicated by SEM image.

2. The higher codeposited nano $\mathrm{SiC}$ particles was obtained at medium stirring rate of $250 \mathrm{rpm}$ in this research.

3. Mixed crystalline phase with reinforced [211] crystal orientation was obtained in case of composite coating by XRD analysis.

4. Highest Vickers microhardness $(575 \pm 10 \mathrm{Hv})$ was achieved at $250 \mathrm{rpm}$ of stirring rate.

5. The lower and constant coefficient of friction value was observed in sample prepared at $250 \mathrm{rpm}$ of stirring rate.

From the results, we can concluded that the $250 \mathrm{rpm}$ stirring rate is found to be optimum stirring rate for the electrochemical codeposition of Ni-SiC composite to get better surface morphology with improved microhardness that gives anti frictional properties.

\section{ACKNOWLEDGEMENT}

One of the authors (Kailash Hamal) is thankful to Global Research Laboratory, Sun Moon University, Korea for all the laboratory facilities and University Grants Commission for partial thesis support.

\section{REFERENCES}

[1] Gyawali, G., Adhikari, R., Kim, H.S., Cho H. and B., Lee, S.W. 2013. ECS Electrochem. Lett. 2: 7-10.

[2] Narasimman, P., Pushpavanam, M. and Periasamy, V. M. 2012. Port. Electrochim. Acta. 30: 1-14.

[3] Mazaheri, H. and Allahkaram, S. R. 2012. Appl. Surf. Sci. 258: 4574-4580.

[4] Bahadormanesh, B., Dolati, A.and Ahmadi, M.R., 2011. J. Alloys Compd., 509: 9406-9412.

[5] Yang, S., Liu, H., Han, S., Li, Y. and Shen, W. 2013. Appl. Surf. Sci. 271: 210-215.

[6] Shi, L., Sun, C.F. and Liu, W. 2008. Applied Surface Science. 254: 6880-6885.

[7] García-Lecina, E., García-Urrutia, I., Díez, J. A., Morgiel, J. and Indyka, P. 2012. Surface and Coatings Technology. 206: 29983005.

[8] Baghery, P., Farzam, M., Mousavi, A.B. and Hosseini, M. 2010 Surface and Coatings Technology. 204: 3804-3810.

[9] Benea, L., Wenger, F., Ponthiaux, P. and Celis, J. P. 2009. Wear. 266: 398-405.

[10] Tsupak, T. E., Valeev, N. N., Dakhov, V. N. and Andreev, I.N. 1987, Zashch. Met. 23: 684-686.

[11] Gyawali, G., Cho, S. H., Woo, D. and Lee, S.W. 2010. Mater. Sci. Forum, 658: 424-427.

[12] Xu, R., Wang, J., He, L. and Guo Z. 2008. Surface and Coatings Technology. 202: 1574-1579.

[13] Berçot, P., Peña-Muñoz, E. and Pagetti, J. 2002. Surface and Coatings Technology. 157: 282-289.

[14] Gyawali, G., Cho, S.H. and Lee, S.W. 2013. Met. Mater. Int. 19:113-118.

[15] Yan, M., Vetter, C.A. and Gelling, V.J. 2013. Corros. Sci. 70: 37-45.

[16] Hyun, J. S., Nam, S.H., Kang, B. C. and Boo, J. H. 2009. Phys. Status Solidi C. 6: 810-812.

[17] Srivastava, M., Grips, V. K. W., Jain, A. and Rajam, K. S. 2007. Surf. Coat. Technol. 202: 310-318.

[18] Bund, A. and Thiemig, D. 2007. Surf. Coat. Technol. 201: $7092-$ 7099.

[19] Zainal, Z., Kassim, A., Zobir Hussein, M. and Hang Ching, C. 2004. Materials Letters. 58: 2199-2202.

[20] Bund, A. and Thiemig, D. 2007. J. Appl. Electrochem. 37: $345-$ 351 .

[21] Gyftou, P., Pavlatou, E.A. and Spyrellis, N. 2008. Appl. Surf. Sci. 254: 5910-5916

[22] Bakhit, B. and Akbari, A. 2013. J. Alloys Compd. 560: 92-104.

[23] Gyawali, G., Cho, S. H., Woo, D. and Lee, S. W. 2010. Han'guk Chaelyo Hakhoechi. 20: 439-443.

[24] Vazquez-Arenas, J. and Pritzker, M. J. 2013. Solid State Electrochem. 17: 419-433.

[25] Low, C. T. J., Wills, R. G. A. and Walsh, F. C. 2006. Surface and Coatings Technology. 201: 371-383.

[26] Orlovskaja, L., Periene, N., Kurtinaitiene, M. and Bikulcius, G., 1998. Surf. Coat. Technol. 105: 8-12.

[27] R. Bazard P. J. B. 1972. Trans. Inst. Met. Finish. 50: 63.

[28] J.Amblard M.F. and Spyrellis, N. 1977. Surf. Technol. 5: 205.

[29] Kılıç, F., Gül, H., Aslan, S., Alp, A. and Akbulut H. 2013. Colloids and Surfaces A: Physicochemical and Engineering Aspects. 419: 53-60. 